\title{
CORRESPONDENCE
}

\author{
Haemodynamic monitoring in the \\ intensive care unit \\ Gillian C Hanson, FRCP, and others..... . 1448 \\ Cutting the cost of the National Health \\ Service \\ J T Hart, FRCGP; P Alwyn Smith, FRCP; \\ N G M Legg, FRCSED; M J Leverton, MB; \\ A R Scott, MB . . . . . . . . . . . . . . . 1449 \\ Long-term care of patients with major \\ illness \\ M H Gough, FrCs................. 1450 \\ Epidemiology and clinical practice \\ E J C Kendall, MD . . . . . . . . . . . . . . 1450 \\ Measles again \\ Christine L Miller, BM; P M J O'Donnell, \\ MB.................... 1451 \\ Prophylaxis of surgical wound sepsis \\ R B Galland, frcs............... 145 \\ Outbreak of infection in a urological \\ ward \\ Mary Anne L Burrow, $M B$, and Penelope J \\ Redding, $\quad$ MB.................. 1451 \\ Preventing infection in clinical \\ laboratories \\ I Leighton, PHD; S S Bakhshi, MFCM... . 1451 \\ Ketotifen in adult asthma \\ W P Maclay, MB . . . . . . . . . . . 1452 \\ Endocrine aspects of liver disease \\ C Gluud, $M D$, and others.......... 1452 \\ Laryngoscopy \\ M G Jacoby, мB. . . . . . . . . . . . . . . . 1452 \\ Second malignancies in Hodgkin's \\ disease \\ G J D'Angio, MD . . . . . . . . . . . . . . 1452 \\ Spironolactone prophylaxis in \\ mountain sickness \\ Squadron Leader G J Turnbull, MRCP. . . . 1453 \\ Cimetidine and thrombocytopenia \\ Victoria $M$ Yates, MRCP, and Rebecca E I \\ Kerr, MRCP................. 1453 \\ Pyogenic liver abscess \\ J P Neoptolemos, MB, and others....... 1453 \\ Surgical treatment of prolapsed \\ lumbar discs \\ L E Wood, MB . . . . . . . . . . . . . . . 1454 \\ Anglo-French contrasts in medical \\ practice \\ A J France, MB................. 1454 \\ Community medicine and community \\ physicians \\ J K Anand, FFCM . . . . . . . . . . . . . . 1454
}

Reimbursement for ancillary help by relatives

Mary J Glanvill, sRN. . . . . . . . . . . 1454

The BMA division

D L Gullick, мв................ 1454

Breaking contracts

E A French, MRCPATH............... 1455

Spoon-feeding in postgraduate training?

D V Bateman, FFARCS . . . . . . . . . 1455

Recertification of specialists

P R R Clarke, FRCS. ....................

Doctors' and nurses' pay

T S Wilson, FRCPATH; S P Marr, MB . . . . . 1455

Early retirement of consultants and

the registrar bulge

R L Bishton, FRCPATH.

Points Exercise training in chronic bronchitis (Veronica Sinclair); Morbid preoccupation with bowel habit (C J Tierney) Giving medicine to young children (Penelope M Newman); Ruptured spleen after electric convulsion therapy (D Gordon); The passing of a custom ? (S A B Black); Falkland Islands interlude (S F Szanto); Setting a bad example? (G Parker); Contrasts in medical practice

(J Moss)................. 1456

\begin{abstract}
We may return unduly long letters to the author for shortening so that we can offer readers as wide a selection as possible. We receive so many letters each week that we have to omit some of them. Letters must be signed personally by all their authors. We cannot acknowledge their receipt unless a stamped addressed envelope or an international reply coupon is enclosed.

Correspondents should present their references in the Vancouver style (see examples in these columns). In particular, the names and initials of all authors must be given unless there are more than six, when only the first three should be given, followed by et al; and the first and last page numbers of articles and chapters should be included. Titles of papers are not, however, included in the correspondence section.
\end{abstract}

\section{Haemodynamic monitoring in the intensive care unit}

SIR, - The challenge of haemodynamic monitoring in intensive therapy consists of supplementing clinical observations with the least demanding set of measurements which gives adequate information on circulatory function in any one kind of patient. Your leading article (12 April, p 1035) contains a valuable discussion of the physiology, but appears to give pride of place to the inferred measurement of left atrial pressure by pulmonary artery balloon catheter. Even in the relatively restricted field of coronary and postcardiotomy care on which it concentrates, a measure of cardiac output and its response to therapy is of primary importance. Thus mortality in coronary care is much more strongly associated with inadequate cardiac output (which passed clinically undetected in about $20 \%$ of postinfarct patients) than with excessive left atrial pressure. ${ }^{1}$

The majority of units, however, encompass a wider spectrum of disease; and it is our experience that haemodynamic monitoring is generally required for different reasons-in particular, optimisation of artificial ventilation in a patient haemodynamically compromised. Pulmonary capillary wedge pressure often ceases to reflect left atrial pressure at high levels of positive end-expiratory pressure, but oxygen saturation in right heart blood samples should continue to indicate the adequacy of cardiac output. ${ }^{3}$ Little mention either was made of sequential monitoring of right atrial pressure following a fluid challenge $^{4}$; the clinical palpation of femoral artery pulse pressure and hourly urine output in association with this manoeuvre; and the fact that an isolated high reading of right atrial pressure may reflect increased intrathoracic pressure, poor pulmonary compliance, or increased pulmonary vascular resistance.

The insertion of a Swann Ganz catheter in desperately ill patients is not always easy, especially when the cardiac output is low; and it is essential that appropriate therapy is not omitted while catheter placement is awaited. We have found a recent development to be convenient and effective in the circulatory management of a substantial proportion of seriously ill patients. Transcutaneous aortovelography ${ }^{5} 6$ is a non-invasive Doppler ultrasound technique which allows recordings to be taken of mainstream blood flow velocity in the aortic arch. Reproducible measurements $(7 \%$ SD) proved obtainable by relatively inexperienced personnel from a transducer applied to the suprasternal notch. While these do not allow absolute cardiac output to be calculated, they satisfy the clinical requirements for which cardiac output measurements are usually indicated: firstly, they reflect serial percentage changes in cardiac output over a wide range with good accuracy (deviation from exact proportionality with reference techniques equalled $9-13 \%$ SD ${ }^{7-9}$ ); and, secondly, we have found them consistently to give a useful measure of the degree of depression or elevation of cardiac output. ${ }^{610}$ In addition, the waveform of instantaneous aortic blood velocity gives valuable evidence of the condition and co-ordination of the left ventricular myocardium and its inotropic state. ${ }^{6}$

Measurements typically taking one minute can be made at the bedside by non-medical personnel, and may be repeated as often and for as long as required. Failure to obtain adequate signals by the normal non-invasive approach, which is visually evident from the real-time recordings, is limited to a small percentage of patients (largely those with lung hyperinflation). We have used the Transcutaneous Aortovelograph (Muirhead Medical Ltd, Beckenham, Kent) to optimise circulating blood volume, dosage of inotropic agents, positive end-expiratory pressure, pacemaker rate, and balloon pump settings, for evaluating the response to afterload reduction and as a rapid check on the presence and severity of some congenital and acquired cardiac defects. ${ }^{6}$

Several years' experience in centres specialising in intensive and coronary care cardiology, anaesthetics, and clinical physiology suggest that transcutaneous aortovelography-often used in conjunction with other relatively undemanding measurements, such as that of central venous pressureoffers a convenient and reliable way of managing circulatory function. It is to be 
hoped that with increasing availability of the instrumentation others will contribute to its evaluation and will benefit from what in our hands has proved a valuable new tool.

Gillian C Hanson

Whipps Cross Hospital,

London E11

A J MEARNS

Bradford Royal Infirmary,
Bradford, Yorks BD9 6RJ

L H Light

Clinical Research Centre,
Harrow, Middx HA1 3UJ ${ }^{1}$ Forrester JS, Diamond GA, Swann HJC. $A m \mathcal{F}$
Cardiol 1977;39:137-45. Cardiol 1977;39:137-45.
1974;109:270-7. CR, Older T, et al. Arch Surg 1974;109:270-7.
Lee J, Wright F, Barber R, Stanley L. Anesthesiology
1972;36:472-8.

Sykes MK. Ann R Coll Surg 1963;33:185-97.

Light LH, Cross G. In: Roberts C, ed. Blood flow measure ' Light LH, Sequeira RF, Cross G, Bilton A, Hanson
GC. $\mathcal{F}$ Nucl Med Allied Sci 1979;23:137-43.

GC. F Nucl Med Allied Sci 1979;23:137-43.
Sequeira RF, Light LH, Cross G, Raftery EB.

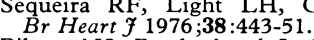

Bilton AH, Brotherhood J, Cross G, Hanson GC Light LH, Sequeira RF. f Physiol 1978;281:4-5P. Distante A, Moscarelli F, Rovai D, L'Abbate A I Nucl Med Allied Sci in press.

10 Light LH. $\mathcal{F}$ Physiol 1978;285:17-18P.

\section{Cutting the cost of the National Health Service}

SIR,-Before the war there was a famous tatooist in Waterloo Road. He claimed as his most original client a man who asked for a necklace of spots and above it the legend, "Please cut along the dotted line". I'm sure this was not Dr G N Marsh (3 May, p 1140) (who was quite little then), but the principle is the same: his proposals for a leaner and more effective general practice are (in effect, if not intention) not for a selective reduction in fat but for a beheading. His proposals for economy would cut short just those developments in general practice that are most hopeful for a more effective, humane, and satisfying future; it is the growing, thinking end he would cut off. Not all his proposals are like this, of course: right at the end of his list of cuts he slips in a proposal for, "an increase in the number of health care workers in the community." This is his well-known and sensible proposal for an expanded primary care team with development (in fact, if not in name) of a nurse-practitioner grade. In what sense will this be an economy?

Nurses who take over the role of doctors will have to be trained for it and will rightly demand to be paid for it. There can be no long-term economy from that policy: it is a policy for expansion, fully justified both on clinical grounds and on costeffectiveness, but it will not be cheap. Nursepractitioners will presumably work to protocols. rather than intuitively, as so many GPs still do Dr Marsh ignores the fact that at present a vast amount of necessary work (listening, explaining, examining, investigating, and co-ordinating care) is simply not being done. Expanded teams will be more critical, their work will be more structured, and present areas of neglect will be more difficult to ignore. Medical activity will expand all round as a result of a team approach, and rightly so.

Most advances in medicine consist of finding things not done, or done very badly, and then organising to do them well. This has itself been the most powerful force for true thrift and costeffectiveness, because for the most part we have to find the time for new tasks by discarding old ones. Dr Marsh admits that "we can view with some pride...that the percentage of the gros national product spent on health in the United Kingdom is much lower than in almost all other sophisticated Western countries," but "having seen health care operating elsewhere... I know this is not due to any particular merit in our system but more to the profligacy of the less effective systems in other countries." Our merit in the eyes of thoughtful doctors abroad have chiefly been accessibility to patients, comprehensive care, a clear division of labour between primary and secondary sectors, and minimal administrative overheads because each stage of clinical care is not impeded by billing and means-testing. Yet three of these four positive features are precisely those he wants us to curtail: he wants doctors to be less accessible, the scope of care to be curtailed, and billing or tests of exemption to intrude on both primary and hospital care. The desire to see enly what is "really important" is almost universa (at least some of the time) among doctors; where they differ is in methods of paying doctors that either magnify trivial conditions (by fees fo service) or minimise serious conditions (by capitation). Sorting what is important from what is trivial is not an elementary, easily delegated skill: it is the highest wisdom in medicine. If we delegate that, we delegate doctoring, whether to a nurse or to the patient. Of course, in fair part, we should delegate it; but to improve care, not to reduce taxes.

Cautious, compassionate, and precise consultation, prescription, and referral, which all of us want, can be obtained only by escape from the industrialised, conveyor-belt medicine that is our inheritance in most parts of the country and most parts of the service. We cannot improve eithe prescribing or referral by imposing more rules on our patients, or by applying deterrent charges to use of the service. Improvements will eventually follow from more time given to more explaining more listening, and better records, so that prescription and referral cease altogether to $b$ ways of evading our responsibility to inform and educate and to diagnose and treat to the full extent of our training; from more time given to maintaining that training, by going to meetings, and by reading books and real journals, no chatting with representatives of drug companies or dipping into the weekly comics; and by un repentant pursuit of our traditional aim, smalle lists.

If the price of economy is to surround ourselve with obstacles to consultation, and push our patients around more, should we not conside more carefully what all this economy is for? W certainly have huge economic problems, but where is the evidence that they will be solved by slashing the Health Service? The NHS is a producing as well as a consuming industry. The fact that NHS care is not paid for as a commodity does not alter the fact that a "consumer good" is produced, which is certainly necessary to the morale and therefore the efficiency of any advanced society. For the first time in any peacetime year, by 1984, projected public spending on preparation for war will exceed the whole of that on educatin our next generation; public spending on housin will fall by $50 \%$ when we have more homeless people than ever before; and public spending on industry, energy, trade, and employment will fall by nearly $60 \%{ }^{1}$ Each of us must decide first whether we accept such a warfare state, before we discuss the details of how to dismantle the welfare state it would replace. There is now $38 \%$ unemployment in my community in the Upper Afan Valley, and that is before the axe falls on at least 5000 jobs in the steelworks at Port Talbot; so we do not need to be told that if we want a Welfare State, it must have a wider, more stable social and economic base and a different distribution of investment and power; but we shall not embrace poverty simply to leave riches undisturbed.

There are no quick or easy solutions, forward or backward, to the right or to the left. But the long hard road to better, more rational primary care lies in a democratic rather than an authoritarian direction; health by, for, and of the ordinary people, with all their ordinary ailments, their poverty of knowledge, and their untapped riches or initiative and intelligence. The patients have been patient, and for too long. Are we really to ask them to wait yet longer, so that business lunches can be eaten, and generals can plan their wars, with scarcely a glance at the bill ?

Glyncorrwg Health Centre
Glamorgan SA13 3BL

JULIAN TUDOR HART Dismantling the welfare state. Labour Research 1980 ,
69:94-6.

SIR,-Dr G N Marsh (3 May, p 1140) seems to assume not only that increased costeffectiveness is best achieved by decreasing costs, but also that cutting health service costs is necessary or desirable in itself. May I differ from him on both issues.

The most important need is for an increase in effectiveness, since both the availability of needed health care and its beneficial effects on health are demonstrably inadequate and most unequally distributed. Our position in the international "league tables" of health has been steadily declining as other countries have overtaken us in health-care expenditure, and numerous studies have demonstrated the large volume of unmet need for health care in this country and the consequent vast burden of unnecessary suffering and misery. It is surprising to find a doctor believing that this situation should be viewed with pride.

It may be that Dr Marsh believes that he has identified areas of waste whose elimination would facilitate a redistribution of existing expenditure in favour of increased effectiveness, but few of his recommended cuts would achieve this. General practitioners already find it difficult to attend as fully as they would wish to the needs of the chronically sick and handicapped or to investigate as fully as they would wish the apparently minor symptoms that may represent the early stages of potentially serious diseases.

Dr Marsh provides no evidence for his view that diversion of more work from the hospital to the community services would effect economies without reducing the quality of care. A number of studies have shown that community care is generally more expensive than care in hospital if similar levels of care are maintained. Surely the experience of the psychiatric services following the reduction in hospital beds provides ample evidence that the community cannot effectively accept a transfer of work without at least a commensurate transfer of resources.

The proportional expenditure on health services in this country has grown less and is now lower than in most industrial countries. Obviously, expenditure on health care is in competition with expenditure on education, defence, law and order, industrial reinvestment, and the maintenance of differential individual rewards. If increased expenditure on health care cannot be met by increased total wealth then we could at least reconsider our priorities. As doctors, we should surely wish to put health a little higher.

ALWYN SMITH

\section{Department of Epidemiology and Social Research \\ University Hospital of South Manchester}

SIR,-Dr G N Marsh (3 May, p 1140) should have used a larger charge to explode the myth that more financial resources are 